\title{
AN OPERATIONAL PLANNING INFORMATION SYSTEM FOR SMALL COMMUNITIES
}

\section{DECEMBER 1969 - NUMBER 34}

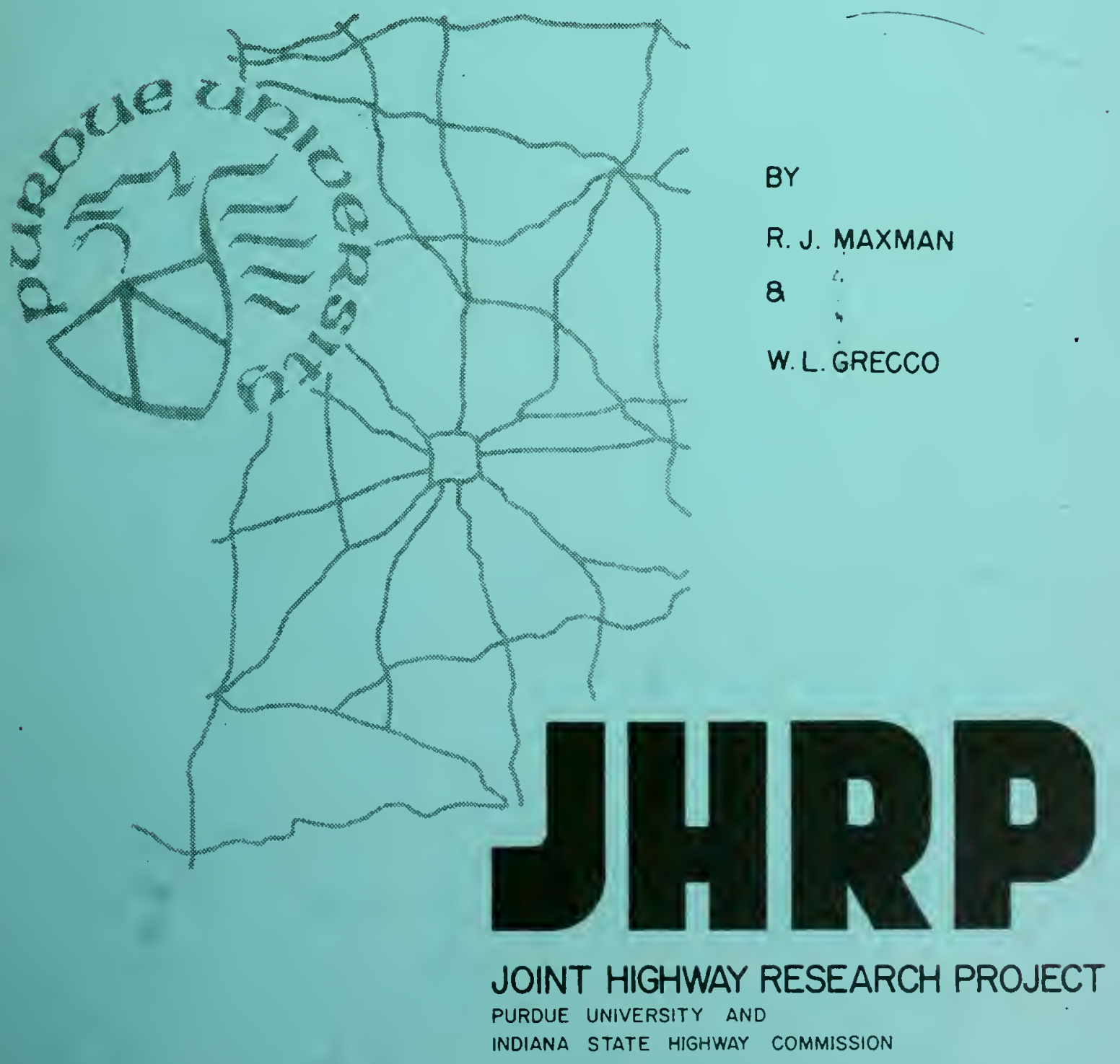



Techical Paper

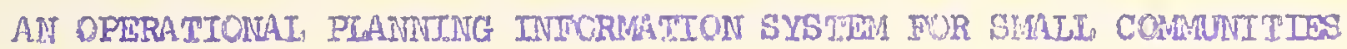

TO: J. Fo Mclaughlin, Dixcotor Joint Highiry Rescarch Project

December 30,1959

FRCM: H.I, Mrichael, Associate Director Joint Highway Research Project:

File 10: $3-7$

The attached Technical Papar "An Operational PIanning Information System for Small Comunithes" has been prepared by Messrs. Robert J. Maxman and killiam I. Crecco. The paper was prepared From JHRP Information Report No. 5, Rach 1963. The research for this paper wes runded by the Public Health Service through the Environmertal Health Institute of Purdue University.

The paper has been accepted for gresentation at the 49 th Annwal Meeting of the Highwy Research Board January 1970. It will be published by the Board during 1970. Whe pacer is presented to the Bord for information.

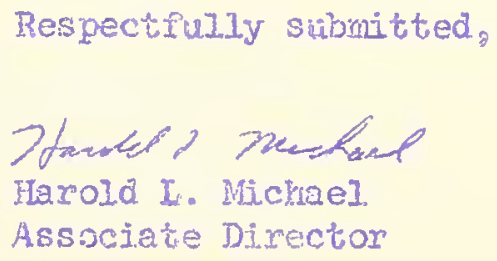

HLWM:.0⿰冫
ce: Fo Io Ashbaucher
H. I. Dolch
W. H. Goetz
W. I. Grecco
G. K. HaIlocis
M. E. Harr
R. H. Harrell
J. A. Havers
V. H. Harvey
F. B. Mendenha II
R. D. Miles
C. F. Scholer
M. B. Scott
W. T. Spencer
II. R. J.Wolsh
K. B. Moods
E. J. Yoder 
Digitized by the Internet Archive in 2011 with funding from

LYRASIS members and Sloan Foundation; Indiana Department of Transportation 
AN OPERATIONAI PYANNIMG INFORIATION

SYSTEM FOR SMATL COMUNTPIES

R. J.Maxman, Transportation Planner, Montgomery-Green County Mransportation and Development Planning Frogtam, Daytom, Onio and

W. I. Grecco, Professor of Civil Eigirieering, Puraue Oniversity.

INFORRATIVI ABSTRACI

The wealth of data collected on the urban area by a mitiplicity of people for a multiplicity of purposes has led to an ineficicient, disorganized utilization of resources for data handing. Until recently, most of the information collected has been gatrered by a specific group for a specific purpose. This information was not useable by other than the primary data recipient because of its narrow definitions and specific characteristics.

Provided herein is a system whereby data that are coliected only once are useable by all segments of the urban environment. Tniversaliy compatible definitions, aggregation unit, ard procedures are developed. Compter prograws were developed to handle the data for the system. The Environmental lata Storage and Retrieval iystem (EDSARS) will make a useful tool for ali segments of the uroban ervironment by putting all 
generally useable data in one place with one set of definitions and aggregated on one useful module, utilizing one set of data handling procedures. The basic unit of data collection was established on a parcel basis, thereby providing a high degree of flexibility in data aggregation.

The conceptual development of information theory as it applies to urban data systems was first explored. The actual conceptual development of EDSARS is explained next, followed by the operational procedures needed to utilize the EDSARS system.

\section{INTRODUCTION}

\section{DATA NEEDE}

Fundamental to the planning process is the development of alternative plans which are provided to the decision maker for action. These plans develop as a result of thorough analysis of proper and sufficient data. Analyses are good as, but no better than the data quality. The present trend seems to be to seek more symtomatic relationships, which implies more data variables. Today it appears almost natural for researchers to add additional variables to the correlation analysis for the purpose of increasing the amount of variability of the dependent variable that can be explained. In spite of the general knowledge of the costliness of data collection, more data are being collected by more people for more reasons than ever before.

The value of data for proper analysis is not under question. The critical point is the efficiency of the entire data system, not from the standpoint of an individual user but in terms of total system costs. Data are being collected on many aspects, from the individuals' health to the number of trips he makes. In the past, most of this information has been gathered by a specific agency for a specific use, each agency applying its 
own individualized definitions to the data. For example, def'initions of land use density can range from trips generated per acre to persons per square foot of flloor space. The definition has always depended upon the information user. This multificity of àta definitions and uses results in a hodgepodge of data, collected miny times by many agencies and many times without knowleage of each other's efforts ( 1 )*

Public agencies gather much of their data for normal operations; these data could be very useful to other agencies at little additional cost, if only common definitions and parameters could be established. Without these common definitions and parameters it is difficult for each agency to visualize the urban environment except in the perspective of its own narrowiy defined information requirements.

Each urban area has developed a multiplicity of plans to channel the growth of the area in a manner that is deemed best for the community as a whole. Up to the present, just as the different agencies collect and use their own data, so do the various urban studies. While a Recreational or School Plan may use much of the data collected in a Transportation Study, the difierence in data definitions and aggregation units makes the information nearly useless for any study other than the one that collected the data.

There are many segments of the wrban environment which desire information on the community. The present means of getting this information is for each to go out into the urban area and collect the data directly. Any company, organization, or group that presently wants data on the community must collect the information itself or accept the narrow definitions of the data now established by existing goverrmental groups or studies.

* Numbers in parenthesis refer to numbers in Iist of references. 
In order to facilitate the wse of data by other than the primary information receiver, a set of universally compatible definitions is needed. This set of definitions is not impossule to develop if one attempts to direct the collection of "pure" data. The term "pure" simply means that the information should not be aggregated before collection. For instance, when square feet of space is collected, it should be recorded as square feet, not square feet per some other dimension. For example, square feet per employee may be useful to an industry, but square feet of birilding and number of employees is much more useful for planning purposes while still. serving the origing. purpose.

The data system that is described below seeks to develop a tool for urban decision making that utilizes data from many sources and makes this information available and useable by other sectors of the urban community.

\section{The Sccpe}

The project described inyolved the development of an urban data system for an area of approximately 100,000 population. The Lafayette-West Lafayette area was used to demonstrate the application of the developed system. The Greater Lafayette area had under consideration the conduct of a Land Use and Transportation study. In anticipation of the development of these data, this planning information system was developed. The system was to be much broader than the proposeä study and is refierred to as the Environmental Data Storage and Retrieval System (EDSARS)。

The first developmental problem involved choosing the degree of sophistication needed for such a system. This involved choosing a particular level in a hierarchy of data system complexity. Once the level of sophistication had been decided, the basic data collection and aggregation module was chosen. The data to be used was decided along with specific definitions 
for each data item. The methodology for entering these data into the system was developed along with updating procedures to keep information current. A logical and easily useable means of data storage and retrieval was developed to facilitete the use of the system by a wide variety of userริ

\section{DESCRIPUION OF ERSARS}

\section{Ievel of Data Sophistication}

The information used in the Erwironmertal Data Storage Retrieval System (EISARS) is taken from the level in data hierarchy of a data Library. Banked data, which is another level in the information hierarchy, are organized into machine records but need not be functional or logical in format. Raw data make up the lowest level of data sophistication. These data are not machine digestabie snd therefore are not useable in an organiged data system. The data library informtion is logical and functional in format and can be mpated, searched, and retrieved; these roquirements are essential for ary uxbar data system.

\section{Level of System Sopkistication}

The three levels of system sophistication vary in the complexity of models incorporated. The first level uses no models, the second atilizes specialized models, while the third level uses simulation. EDSARs, being an attempt at developing the initial phase of an urban data system, utilizes the first level of sophistication. The system contains tabulated data but no specialized or simulation models. It is felt that the model requirements will evolve from the demands of the vsers on the data system. The addition of models to the system can be made within the present format; the data in the system will directly feed any models developed in the future. 
The computer hardwre that is incorporated also influences the level of system sophistication. EDSAFS Ltilizes the CDC 6500 compster at Purdue University. This is a general purpose computer; the programming language wsed is Chippewa Fortran. The data systers can be initialized and information retrieved or updated by merely subntting the correct program deck to the computer science center. The updating, totrieval or initialigation will be run just as any other job that is subritted to the computer. The Intormation for ERSARS is now storea on tape. As the system is inzialized and the amount of stored information frows, the incorporation of a "aisk pack" wili become feasible. A "disk peck" is a montable disk storage device tivat enabies random access of informeton. mis direct access feature will save raluable computer time when the system searches large quantities of deta.

Whe decisions on the level of system sophistication were the result of many factors. Models were not incorporwted into the system because of the necessity of actial data to test the valuity ot a model. This project outlines the initialization of ENGRS withox actualy inserting revi data. The amount of data needed to initialiae the system maks initialization another entire project of at less one to tro years in duration. Once the Initialization is complete, then the addition of molels can be considered. The decision of using the CDC 6500 computer was made ir light of the hardware avalable. Purdue Thiversity now has an IBM 7094 computer wich coula handle a data system such as EDSAES. Wowever, the 7094 is a second generstion computer; this type of compurer is now in the process of being phased out by many organigations; being weplaced by a "trira generation" computer such as the cno 6500 computer. Any work done in the future on data systems will most probably be done on the more advanced equipment such as the CDC 6500. Whe use of Chipgewa Fortran was the result of the authors: 
knowledge of the langmage and the tact that the Fortran developed for the CDC system is quite efficient in its data wandling capabilities。

\section{Data Module}

The data module chosen for ETsAF is the parcel. This aggregation moüule seems to be almost the univerwil choice by existing urban data systers. The parcel provides a fexible, multi-purpose base from which to work. The data to be incorporated into an urban data system are easily keyed to the parcel. The tagging rethods, whoh will be discussed below, work well with the parcel module. The parcel forms very useful aggregation. unit in that it is the largest comon devominator that can be used to build zones. Any zone in an urban area wan be represented foirly accurately, by a composite of parcels. This gives the system maximum flexibility in the designation of zones while containing a mimum nuber of data units.

The parcel in EDSAKS is defined as all contiguous land under one omership and one general land use. This definition closely parellels the parcel used in assessors " records. If tro adjacent pieces of land are owned by the same person and used for the same purpose, they would be listed as one parcel. If two adjacent parcels had different uses, they coild be listed as two parcels. This definition, being genexal, allows a certain measure of ambiguity in the designation of a parcel: the system has the facility, however, of being able to join two ow more parcels into one new parcel, or break up one parcel into two or more parcels. This facility for redefining parcels allows the system to estublish its own equilibrium as the data are used and reevaluated.

A special definition of the parcel is utilized when coding rights-ofway. Each street segment and utility right-of-way is coded just as any other parcel. A street or right-of-way is broken down into block long 
segments if the biock length is 500 feet or less; if the bloak length is Ionger than 500 feet, the block is broken down into segments of 500 feet or less. An intersection is taken as a street parcel. The parcel boundaries are defined as the migh-of-may Iine for the street segments. An example of an area divided into parcels can be found in Figure 1 .

\section{Data Tagging Mthods}

ERSARS uses both the name method and lacation method of tagging data. whe name tag utilized is the street adaress of a builaing or empty parcel. The street number, name and type (e.go, mroive, Street, Iane, etco) are all noted in the name tag of the parcel or builoing. For waral areas, the street number is replaced by the rural route number, and the street rame is replaced by "Rural Ronte." The name nethod of tagging gives tise system the facility of locating data for the user on a basis that is familiar to 2.1 segments of the urban environnent. Street addresses are universaliy known and understood, and, therefore, erable all potential users to be familiar with at least one retrieval metboa.

Street segments are coded by the strest name and the number (in hwnareds) of most of the houses on the atreet segment. A street segment along a street called Main Street, where kouse numbers go from 100-225 would be coded as $100 B$ Main street. Whis indicates that this is the one hudred block of main street. This gives the benefits of the name tag to street segments as rell as individual pareis and buildings.

The location tag utilized by EISs system which is superimposed over the eritire development area. The grid coordinate uses one foot as the basic unt. The parcels and street Iengths are tagged by the coordinates of their approximate centroid. The actual digitizing of the coordirates is accomplished by an automatic 
coordinate digitizer. By utilizing a location tag, interral logic is aded to the data in EDSARS. The coorainates facilitate the retrieval of data on an areal basis. Data for certain geographical segments of the development area can be directiy retrieved with the use of the coordinates. Density computations become immedigtely possible with the use of coordinates.

The utilization of rectangular grid coordinates provides another very useful capabilitity. A zone, sucn as a Census Tract or Transportation Zone, can be represented by the grid coordinates of its boundaxy. This is accomplished by representing the zone by a series of triangles ard digitizing . the coorainates of the vertices. Iy representing zones in tris way, a dictionary of wone names and grid coordinates is developed. When any information is desired on a zonal. basis, the coordinates of the zone are read and each parcel is tested to establish whether or not it lies within the zone in question. The intormation for each parcel within the zone is then retrieved and aggregated thereby giving information on the desired zonal basis. Figure 2 shows a zone broken into triangles for coding.

In order to coordinate the actual data incorporated into the system and the tags for each parcei, a dictiondry with the parcel number, building number, and street address (or block number for street segments) developed. Another file coordinating each pared nuber and grid coordinate is then initialized. The actual data are stored in conjunction with a parcel number. The data are related to the name and location tags through the parcel number-building number $\approx$ street adoress dictionary and the parcel number-grid coordinate dictionary. pare panber is merely a unique number of 1 to 6 digits given to each parcel. The numbers need not be consecutive or have any logical order. The only requirement is that each parcel have one and only one unique number. 


\section{Data Dimensions}

The definition of land use developed by the Metropolitan Washington Council of Governments was utigized to aid in determining the data needed to define the different areas of land use. Data were examined in the light of how well they defined:

I. Type of activity

2. Type of structure

3. Type of Iand use

4. Intersity of use

5. Aesthetic qualities

6. Restrictions on use

7. Nuisance characteristics

8. Economic functions (2)

In order to completely describe she wrban environment, the information on each farcel is broken down into three categories:

1. Farcel Information - information on the parcel itself, including dimensions, restrictions, zoning, nee, eto.

2. Building Information . intormation on each building on a parcel, including age, value, type of construetion, condition, size, etc.

3. Establishment Information - specific information on each unit within a buidding such as a business, a dwelling unit, etc, including space use, number of employees, nuriber of residents, age of residents, number of vehicies, etc. 
I. Parcel Information
1. Land use
13. Zoning
2. Ownership
14. Zone change request number
3. Frontage
15. Variance number
4. Area
16. Comprehensive Plan use
5. Year of subdivision
17. Utilities
6. Assessed value of land
18. Farking spaces
7. Easement
19. Loading area
8. Landmark
20. Assessed value of improvements
9. Neighbornood characteristics
21. Total assessed value
10. Land appearance
22. Sale date
11. Number of structures
23. Sale price
12. Year of zoning change
24. Nuisances

(The following data are collected for street segment parcels)

25. Intersection

26. Iength of segment

27. Right-of-way width

28. Farement width

29. Functional class

30. Structural composition

31. Per cent grade

32. Average daily trafíic

33. Number of accidents

34. Traffic control signs and signals
35. Speed limit

36. Curb parking regulations

37. Curb type

38. Sidewalks

39. Number of lanes

40. Loading zone

41. Bus route

42. School route

43. Access control

44. Condition 
II. Building Information
1. Year built
9. Basement
2. Type of construction
10. First foor ares
3. 5ype of structure
11. Number of aweling units
4. Building condition
12. Building setback
5. Year of latest building permit
13. Required setback
6. Cumblative cost of builoing
14. Rehabilitation cost
7. Number of floors
15. Type of building code violation
8. Total floor area
16. Number of building code violations
17. Number of establishments

III. Establishment Information
1. Space use
8. Vehicles owned
2. Total number of employees
9. Police calls
3. First floor area
10. Fire calls
4. Total floor areas
12. Welfare payment
5. Number of rooms for rent
12. Number of commicable diseases
6. Number of residents by sex and age group
13. Type of comminicable dìseases
7. Family income
14. Fent

Each piece of data that was entered into the system was judged to be important to the planning commurity, able to be updated, and relatively easy to collect. Data that were too expensive to collect or not updatable were not incorporated into the system. 


\section{OPERAMION OF EDSARS \\ Data File Characteristics}

The data in EDSARS are established in four separate files. The first data file contains parcel numbers and parcel grid coordinates. Each parcel is given a unique number to identify it as a data entity; this number is correlated to the grid coordinates of the approximate parcel centroid by the Parcel Nurnber Grid Coordinate File. The second data fille contains the parcel number, building number and address of each building in the system. In the case of a pareel with no building, the building number is listed as zero. Each building is given a unique number on a parcel, and coordinated to the correct address by the Farcel Number-Building NumberAddress File. The third data file contains the parcel number and all general data on that parcel. The data for each parcel are correlated to the street aduress and grid coordinate via the parcel number whe fourth data file contains zone names and the coordinates of the zone boundary".

These four data files make up the data storage portion of EDSARS. The actual data is stored on tape and can be manipulated by a set of package programs. The first set of programs is used to initialize the system by reading cards and writing the information on tape. The second set of programs is used to incorporate more data items when they become available. The third set of programs is used to read the data tape and write on paper. This set of programs is used to check the other program sets and to give a complete list of all data in the system. The fourth set of programs is used to update the values of data items in the system when current information becomes available. The fifth and final set of programs is used to retrieve information from the system for special user purposes. The following is an explanation of the package programs and procedures for using them in EDSARS. 


\section{General Program Information}

Each of the programs discussed belor is used to manipulate the data in EDSARS. When data cards are to be read into the system, a card with ${ }^{4} 7,8$ and $9^{\prime \prime}$ punched in column one most follow the main body of the program and precede the actual data cards. When reading General Data cards, the last card should have a "99" in columns seven and eight. This indicates end-of-data to the system. The Last deta card in the Zone-Grid Coordinate File, the Parcel Number-Building Number-Address File, and Parcel NumbeGrid Coordinate File should be blank to indicate end-of-data to the system. Whe last data card is followed by a card wth ${ }^{\circ} 6,7,8$, and $9^{\prime 2}$ punched in colum one. This indicates end-of-program to the computer. If no data cards are used in a program, the ${ }^{\circ} 6,7,8$, and $9^{\circ 8}$ card immediately follows the main body of the program.

\section{Data File Iritivilization}

Parcel Number-Grid Coordinate File

The initialization of the Pareed Nuber Grid Coordinate File occurs first. To Initialize this file, the coowdinate digitizer of the Joint Highway Research Project at Purdue was utilized. An accurate base map of the entire development area was placed on the digitizer and a point 1,000 feet south and 1,000 feet west of the southwestern corner of the development area was set as point $(0,0)$. Key points on the base map were digitized; the digitizer gave readings in inches and these readings were then converted to feet; the conversion depended upon the scale of the map utilized.

The key points digitized were the intersection of street center lines. The key points that are located on the base map were digitized on the more accurate maps, and the coordinates of these key points served as reference coordinates for the aigitiong of all parcels. 
Each map to be digitized, other tran the base map, was first broken up into parcels and approximate centroúds located as shown in Figure I. Consecutive parcel numbers are then written on the map for each parcel. The map is placed on the digitizer, its key point located (for coordinate conversion to the base system), and then each parcel centroid can be digitized. Tine digitizer will purch the parcel number and the grid coordinates on an IBM card whin can then be fed into the computer for coordinate conversion.

The data caras for actual initialigation of this data file are read into the system via the "Initialize Farcel Nuber-Grid Coordinate-File" Program. The data cards for this file should have the format shown in Figure 3. This figure can also serve as a sample coding sheet. The parcel number is piaced in columns $1-6$. The $\mathrm{X}$ coordinate is placed in colums 8-13, and the $Y$ coordinate in colurms 15-20. When more information becomes avaifable, a Program titied "Fead More Information For The Parcel NumberGrid Coordinate-File is used. Ming data file locates all of the parcels in the development area and coordinates the parcel location to a particuiar parcel number. This number is the ldentifying tag in the syster used to locate all data that pertain to this particular parcel.

\section{Pareel. Number-Biliding Wurber-Adaress File}

The Farcel Nurber-Builaing Numeradaress File is initialized by putting the Parcel Number in colunns $1-6$ and the Building Number in columns 20-21. The street or rural route number is placed in columns 22-27. If the parcel is a street segment, the biock number is placed in columas 20-26 with a " $B$ " in column 27 to inalcate "street block." All of these numbers should be right justified. Columns 30.69 contain the street name or "Rural Route." The name should start in columir 30 and be purched on the card just 
as it appears in the tom directory with one colum between each word in the name. The type of street is coded in column 70-72. Format for this file card can be found in Fig. 3. Wher more information becomes avalable, a program titled "Read More Information Fox whe Parcel Number-Building Number-Address File ${ }^{n}$ is used. This tolle coordinates each building, vacant parcel and block segment with a partionda adress in the development area.

\section{General-iata File}

The fille for general data is inzialined atter each parcel in the development area has been given a unique numer. The format for General Data cards can be found on Figure 4 ; this toigure can also serve as a sample coding sheet. Whe ol card is used for every parcel in the development area. The 02 card is usea hinere the parcel has a use other than right-of-way. A 12 card is used in piace of the 02 card when a parcel is $a$ might-of-way. If the parcel has mutiple land use, zoning or comprehensive land use, an 11 card is used to suppienent the 01 and 02 cards. Each building on a parcel is represented by the information on the 03 card, and each establishment (dwelling unit, business, office, etc.) in a building is represented by an 04 card. Trie Irformtion in the General Data F'ile is broken into three categories. The fust category is land use information and is represented by the 01,02 , or 12, and 12 cards; the second category is building information which is represented on the 03 card, and the third category is establishment information which is represented on the 04 card.

Each data item in the system is giveri a specific name. This name is used to refer to the particular data item within the system.

Each building on a parcel is given a number to uniquely identify it; if four buildings exist on one parcel, they rould be numbered 1-4. Each establishment within a building is also given a unique number to identify it. 
Building numbers start at one, with each separate parcel; establishment numbers start at one, with each separate bwilling. A Program titled "Initialize the General Data File" is ised to initialize this data file by reading data cards and writing the inforration on tape and paper as a check. Whe Frogram "Kead Niowe Information For the General Data Frile" is used to read in more information as it becones bvailable.

\section{Zone-Groad Coordinate File}

The last folle to be initiated is the Jone Grid Coorainate File. To define 2 zone, $_{9}$ its bourdary is zccated in the developinent area by the grid corranate system. The zone is broken up into triangles and the grid coordinates of each of the three verutes are coded on data cards. The card format is shown in Figure 3. An exampie of a zone broken into triangies can be found in Figure 2 . whe comdingte of the vertices are placed on the data card by nubering the vertices $1-3$. Point ore is coded first, followed by point two, pcint three, and point one again. The first and last coordinate must be the same in order to close the triangle. The identifying zone name is placed in colums $1-12$, the zone number is placed in columns 15-20. The coorainate of the vertices are placed in colums 22-80 in the format shown on Figure 3 . The gone name starts in colurm $I$. The zone number and grid coordinates are right justified. Frogram "Initialize Whe Zone Name-Grid Coordinate File" is used to initialize this file by reading data cards and writing the data on tape, and paper as a check. ITo read more information into the system as it becomes available the Frogram "Read More Information for the zone-Grid Coordinate File" is used. It should be noted that this file can contain as nany zonal systems as required by the users. Census Tracts, Transportation Zones, School Zones, etc. are all examples of possible zonal systems that could be incorporated into this foile. The inclusion of a particular zoral system is dependent upon the potential use of its parcel aggregation. 


\section{Read Programs}

There is a general class of program in EDSARS that will read the data fille tape and print the information on paper. These programs should be used after reading in more date or updating the system to check the accuracy of the tape fille. Trese programis car also be used to obtain a complete list of all information on the tape. These Fead Programs will read the Parcel NumberaGrid Coordinate file and print a complete inst of the tape file, read the Parcel Naberwbilding Nimberwddress fille and print a complete list of the tape, read the General Data fiile and print a corrplete list, read the Zone-Grid Coordinate file and print a complete listing of this information.

\section{Update Frograms}

In order to change any of the inforration in the systern or wpdate the information, a set of update programs has been developed to replace the old information, with the new. This is accomplished by using the initializing programs to make a tape fille of the new information. This new information file and the original folle are then used to initialize a new tape file with all of the new information incorporated into it.

AlI of the wpdate programs require that the new data cards be identical to the original in format. Whe new cards should be complete - all information that is not changed should stili be punched on the update card. The new information is punched on the card replacing the old in the same format. These cards are then used to form the update file. Any data card that has no data changed need not be entered into the update foile, but any card that has any piece of information cinenged must be completely repunched with all of the rew and unchanged inforration. 
Retention of old lata Files

A decision on how many old data files should be kept needs to be apprcached at this time. Data files represent current data for a certain period of time. Whe corparison of data foiles for different time periods can yleld useful information on trends that exist in the development area. It is felt that files should be updated th least once a year. These yearly files should be retained for at least a pexiod of five years. The final decision on this policy is, of course, up to the initializing agency.

\section{REREFTED PEOGRAMS}

To retrieve information from the data files for special purposes, there are a set of programs in EDSARS which give specific information for the special purposes of the user. me following programs were desigred to be general in their characteristics so the specific user needs could be satisfied. The retrieval programs arilable in the system are:

a. To retrieve a list of $Y$ and $\mathrm{x}$

b. To retrieve the sum of $Y$ sor a specific $X$.

c. To retrieve a list of I for a specific $\mathrm{X}$.

d. To retrieve $X$ for specific pareel numbers.

e. To retrieve a parcel number and building number for a specific address.

f. To retrieve a list cf parcei nubers tor a specific zone.

\section{COROULSIONS}

The following conclusions about Hnsiks and its potential can be made:

1. EDSAFs should facilitate effic cient and economical handing of planning data for an area of about 100,000 popuiation.

2. The utilization of gereral purpose computer and general purpose programming langwages should make InsAns available to most metropolitan areas in the United States. 
3. The concept of a unified data system is the most important contribution of EDSARS.

4. The data proposea for FHAFE the most usable and easily obtainable information available to she wrban area.

5. The incorporation of a flexible method of representing zones by their location is essential to an effucient wrogn data system such as EDSAPS.

6. whe information for an urban data system showid be in three separate files so that one file can be updated and improved without disturbing the other fules.

7. Zone names and boundaxy locations should comprise one file; parcel numbers and parcel location comprise another folle; parcel numbers, building numbers, and street address should compise the third file; and the fourth file should be made ap of general data.

8. Whe best unit for dats colluction is the parcel.

9. Whe data system should be fuxible so that improvements can be made as used and technology increases.

10. The streets and rights of why skould be represented as special parcels in orjer to ensure tull terwitorial and information coverage.

11. A11 data incorporated should be potentially useful and updatable.

12. Utilizatzon of applicable theory and practical experience of existing data systems are needed to develop a useful, efficient and ¿mproved data system.

The concepts that are represented by these conclusions when tied tagether into an urban data system such as ECAARS give the planning community and the urban envirorment as a whole a flexible and useful tool which should make more information awilable to more people at a much lower cost and with mich less effort. 
It is inportant to acknowledge that the conceptual technique for retrieving infoxmation on a zonal basis through the use of coordinates was develoged at the University of Waskington by Mr. Robert B. Dial. Tre

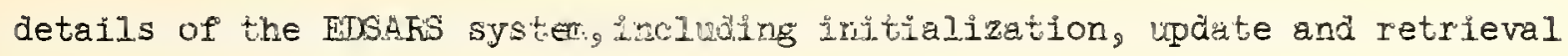
programs, codes wtilized and complete descriptions are available in a Purdue Tniverwity, Joint Highwy Resesrch Project Information Report No. 5, March 1968. Copies are drilable at the cost of reproduction. This project was funded by the Public Health Service through the Environmental Health Institute of Purdie Univeristy。

\section{IJIST OF REHEREHES}

1. Metropolitun Iata Center Project, Wuisa, Okiahoma, February 1966.

2. Interin Report: Metropolitan Flanving Datg From Local Governments, Metropoitan Washington Concil of Goremments, August 1966.

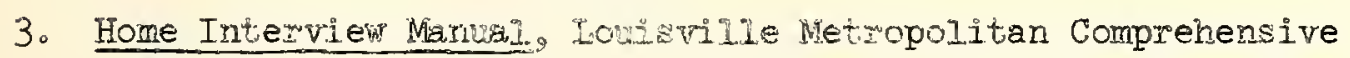
Transportation and Derelopmend Frograng 1965.

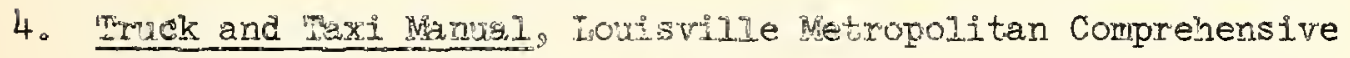
mransportation and Development Frograin, 1965.

5. Erterna Survey Menual, Louisville Metropolitan Comprehensive Transportation and Derelopinent Program, 1965.

6. Land Use Mancal, Louisville dietropolitan Comprehensive Mransportation and Development Frogram, 1965 .

7. Rosd and Street Inventory Marizid, Louisvilie Metropolitan Comprehensive Mransportation and Development Frogram, 1965.

8. Flon Characteristics Marual, Lonisyilie Metropolitan Comprehensive Thronsportation and Development Program, 1965.

9. Accident Study Marual, Iouisville Metropolitan Comprehensive Mransportation and Development Program, 1965. 
10. Parking Study Manual, Loulsvilie Metropolitan Comprehensive Fransportation and Development Prograin, 1965.

11. Routes and Iermän Manul, Louisvilie Metropolitan Comprehensive Transportation and Development Program, 1965.

12. Transportation Facilities Btandards, Louistille Metropolitan Comprehensive Transportation and Development Frogrim, 1965.

13. Population Economic Base Marus, Touisville Metropolitan Comprehensive Mransportation and Development Program, 1965.

14. Planzed Transportation Facilities, wowisvile Metropolitan ComprehensiveTransortation and Development Prograit, 1965.

15. Public mansit Study, Iouisvilie Metropolitan Comprehensive Transportation and Development Frogram, 1965.

16. Development Data, Iouisvilie Metropolitan Comprehensive Transportation and Deveiopment Frogram, 1965.

17. Maxm, Robert J。 "The Data Iowisvilie Transfortation Flan and its Application to Data Analysis," Terhnical Jomana, Fol。 1 , No. I, Jonisville Metropolitan Comprehensive Transportation and Development Program, pp. 1-27.

18. Planning Methodology ard Techniques, cIass notes for CE 6I3, Prof.W. I. Grecco, Furdice University, 1966. 


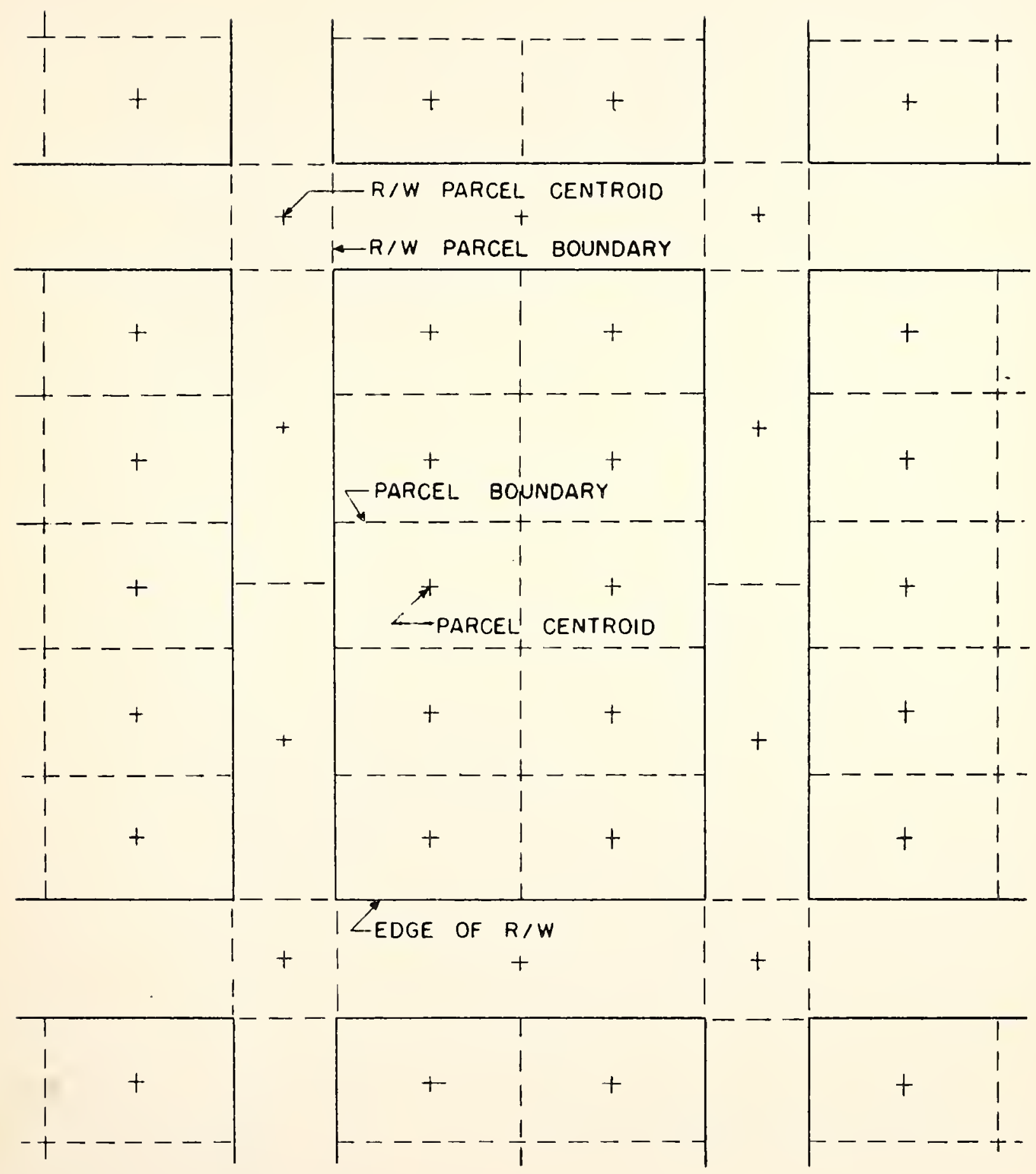

FIGURE I. SEPARATING AN AREA INTO PARCELS FOR DATA CODING 

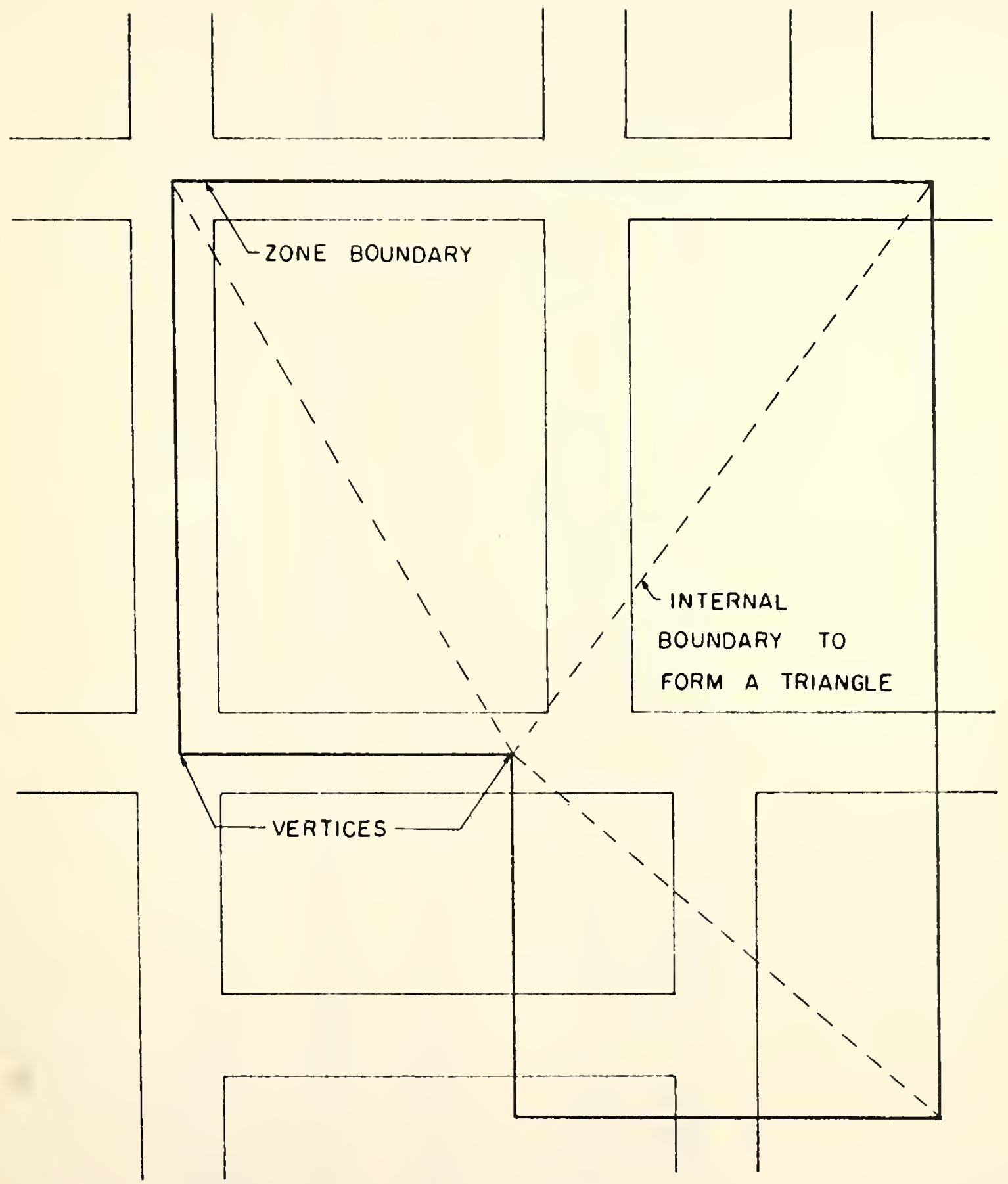

FIGURE 2. ZONE DIVIDED INTO TRIANGLES FOR DATA CODING 


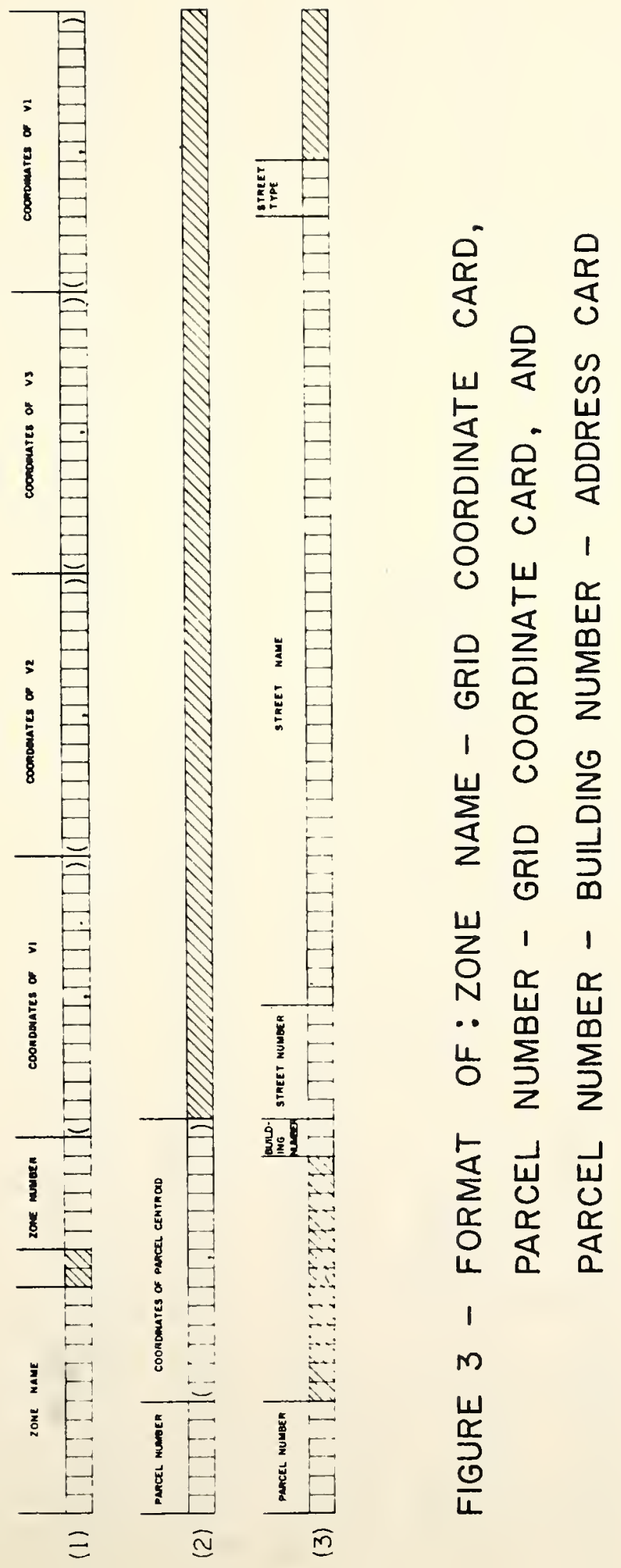



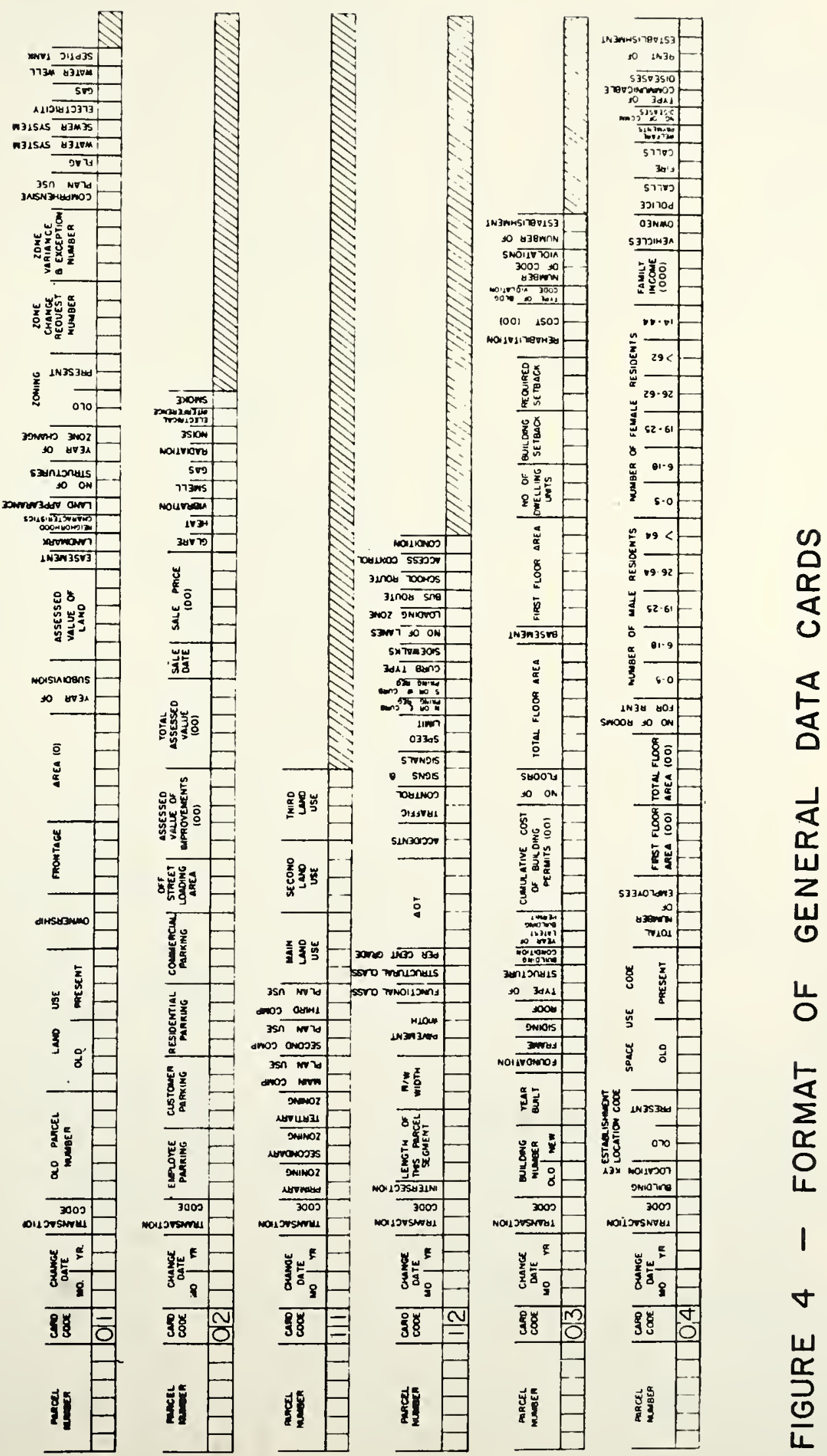
